\title{
Judgment day: Activating computational thinking activities with popular culture
}

\section{El día del juicio final: Activando actividades de pensamiento computacional con la cultura popular}

\author{
Tonia A. Dousay \\ University of Idaho, Moscow, ID USA \\ tonia@uidaho.edu
}

\begin{abstract}
Interest as a learning construct provides more than inspiration for innovation. Dewey recognized the role of interest as a powerful tool to engage learners. Yet, despite contemporary efforts to study the phenomenon, few learning designs recognize this potential. The current paper presents a conceptual framework for integrating popular culture into STEM, using computational thinking competencies as both a critical mechanism and context for application and testing. Interest contributes to motivation through self-regulation, and self-regulation has the power to enhance the cycle of learning achievement and interest. Through this framework, Merrill's Activation Principle provides guidance on why and how we should attend to this cycle. By evoking positive memories related to learner interests, we can enhance other stages of learning disconnected from the initial learning experience. STEM educators and scholars can use this framework and confidently design and evaluate learning activities targeting computational thinking development using popular media and culture.
\end{abstract}

Keywords: STEM learning, learning design, activation principle, situational interest, computational thinking

\section{Resumen}

El interés como construcción de aprendizaje proporciona más que inspiración para la innovación. Dewey reconoció el papel del interés como una herramienta poderosa para involucrar a los estudiantes. Sin embargo, a pesar de los esfuerzos contemporáneos por estudiar el fenómeno, pocos diseños de aprendizaje reconocen este potencial. El presente artículo presenta un marco conceptual para la integración de la cultura popular en STEM, utilizando las competencias de pensamiento computacional como un mecanismo crítico y un contexto para la aplicación y las pruebas. El interés contribuye a la motivación a través de la autorregulación, y la autorregulación tiene el poder de mejorar el ciclo de logro e interés en el aprendizaje. A través de este marco, el Principio de activación de Merrill brinda orientación sobre por qué y cómo debemos atender este ciclo. Al evocar recuerdos positivos relacionados con los intereses del alumno, podemos mejorar otras etapas del aprendizaje desconectadas de la experiencia de aprendizaje inicial. Los educadores y académicos de STEM pueden usar este marco y diseñar y evaluar con confianza actividades de aprendizaje dirigidas al desarrollo del pensamiento computacional utilizando los medios y la cultura populares.

Palabras clave: aprendizaje STEM, diseño de aprendizaje, principio de activación, interés situacional, pensamiento computacional. 


\section{Introduction}

What do a submarine, rocket, and cellular phone have in common? Aside from the STEM expertise necessary to bring these innovations to life, these three devices all find their roots in media and popular culture. For example, Simon Lake drew his inspiration for the submarine from Jules Verne's Twenty Thousand Leagues Under the Sea, Robert H. Goddard found his inspiration in H. G. Wells's War of the Worlds, and Martin Cooper credits Star Trek: The Original Series with inspiring Motorola's objective to build the cell phone culture (Strauss, 2012). Broadly influenced by popular culture, these examples represent the power of interest to drive inspiration and ingenuity.

Interest, in this context, refers specifically to the construct of motivation and holds immense power in terms of learning design. Reeve's (1989) foundational research clarified the difference between interest and enjoyment, "interest contributes to intrinsic motivation by arousing the initiation and direction of attention and exploratory behavior" (p. 83). The implications of interest thus represent a rich opportunity to explore how to initiate attention and how to facilitate exploration. Interest has the potential to support learner autonomy (Reeve et al., 1999) and may manifest in the learning environment through a variety of contexts or approaches, including characteristics of an instructor or peers (Isaac et al., 1999) presence of collaboration in learning activities (Nummenmaa \& Nummenmaa, 2008), and even the physical learning environment (Alsup \& Ford, 2017).

Often dismissed as entertainment or branded as a distraction, Luke (1997) recognized the need to constructively integrate media and popular culture into teaching practice and research. Unfortunately, we know little about the relationship and role between interest as a learning motivation and popular culture and media. Literacy educators, often find value in exploring the cultural and political contexts of books, television shows, and movies. Deconstructing components of perspective, authorship, and readership media helps learners develop critical thinking skills necessary to form judgments (Alvermann et al., 1999). However existing studies focus on the literacy outcomes rather than interest stimulus or long-term implications. Similarly, history and humanities educators find value in teaching about and with popular media to decode messages and critically explore social and cultural issues (Trier, 2006). Again, the discipline has not examined the motivational aspect of this practice. Further, the literature fails to address empirical examples of using or researching popular culture use in STEM disciplines, instead appearing as anecdotal recommendations by teachers and educator resources (see Cunningham, 2014 and Silva, 2019 for examples).

The purpose of this paper is to explore a conceptual framework for integrating popular culture into STEM, using computational thinking competencies as a critical mechanism and context for application and testing. The framework is grounded in computational thinking and motivation, exploring unplugged computational thinking and abstraction as scaffolds to integrate with designing learning for self-regulation through interest. Merrill's Activation Principle provides clarification regarding how the scaffolding supports mental models. Specific examples of popular culture contextualize the framework's applicability.

Judgment day: Activating computational thinking activities with popular culture. Tonia A. Dousay. 


\section{Computational Thinking}

\section{Unplugged}

The intrinsic connection between computational thinking and computer science provides a natural context for skill development but requires clarification. Caeli and Yadav (2020) characterize unplugged computational thinking as the thinking and designing prior to coding. The underlying concept here situates humans as designers and machines as processors of our designs. However, we should not conflate unplugged computational thinking with unplugged computational thinking activities, which "do not require the use of digital devices or any kind of specific hardware" (Brackmann et al., 2017). Early computer science education pioneers such as (Naur, 1970, 2005) provided arguments for unplugged approaches to align with the concept, and interest in unplugged approaches emphasizes the role of humans in human-computer interactions (Bell \& Roberts, 2016).

It bears noting that the omnipresent nature of technology-integrated learning allows for unplugged computational thinking to focus on the concept while using digital tools to support documentation and presentation. For example, consider a lower secondary unplugged computer science curriculum based on challenge projects that used storytelling to teach data representation, algorithmic thinking, and abstraction (Rodriguez et al., 2017). Rich stories and engaging characters present mysteries to solve, appealing to learners' interests in animals (Delilah the Dog) and fantasy (Carnival Fortuneteller). Learners might complete the tasks and documentation associated with the problems using a pencil and paper or any number of digital tools, including a text processor (i.e., Microsoft Word or Google Docs), spreadsheet application (i.e., Excel or Sheets), graphical organizer (i.e., PowerPoint or Slides), or other application. Regardless of the tools used in the activity, unplugged computational thinking activities begin with competencies and practicing their application.

\section{Abstraction in Computational Thinking}

Abstraction, referred to as the essence of computational thinking, requires deconstructing complex ideas to assign meaning and value as we use, create, and modify complex systems and tools (Wing, 2006, 2008). Take, for example, the ubiquitous smartphonefor all intents and purposes a compact supercomputer that engages with cellular and wifi networks to complete complex tasks including information retrieval, data processing, and telecommunication. Nevertheless, the average smartphone user cannot explain in detail how the device is made, nor can they describe how data networks function to enable their device.

Abstracting the idea of a smartphone, some users combine the idea of a desktop computer and corded telephone, anchoring the innovation to two previously known yet independently complex systems and devices. In this overly simplified example, the deconstruction process serves sequential purposes. First, it facilitates forming relationships to associate knowledge. Second, these relationships serve as pathways to exchange concepts. Returning to the example, associating a smartphone with a desktop computer opens the idea of how to use, interact with, or troubleshoot the smartphone

Judgment day: Activating computational thinking activities with popular culture. Tonia A. Dousay. 
similarly to how one might use a desktop computer (e.g., use applications) or a telephone (e.g., make phone calls).

Assumptions about and approaches to teaching and assessing abstraction provide insight into what makes this computational competency particularly dynamic. During their analysis of the tasks underlying the Bebras ${ }^{\circledR}$ Computing Challenge, Izu et al. (2017) expressed surprise at finding abstraction frequently within the challenges designed for the youngest learners, describing it as a complex competency that is advanced and difficult. Despite this assumption, the researchers suggested exploring more ways to incorporate abstraction into early computational thinking education. How we go about such a recommendation benefits from a glimpse at different learning contexts.

The following three examples cut across the lifespan of learning and represent general unplugged computational thinking activity examples. Brackmann et al. (2017) taught abstraction through converting a popular children's song into an algorithm and assessed learners using the Computational Thinking Test with popular characters (e.g., PAC-MAN and ghosts) to conceptualize the core elements of a problem, disregarding irrelevant details. This example represents a macro-alignment between the concept of abstraction and its application, situating the activity in a decontextualized setting. Working at the secondary level, Looi et al. (2018) targeted abstraction by asking learners to design and write an algorithm using natural language (e.g., English), flowchart, pseudocode, or Python code. This example represents a micro-alignment between the concept of abstraction and its application, situating the activity in an authentic context. Curzon et al. (2014) series of unplugged workshops to teach computational thinking to teachers focused on storytelling. Different activities introduced and provided opportunities to practice abstraction, including group discussions focused on analyzing a process for enhancement and deconstructing magic tricks to identify, document, and classify steps. Like the work with primary learners, this approach decontextualizes abstraction for the learner. When examined holistically, these three examples also provide insight into why these types of alignments work for their intended audience.

The first and third examples took a decontextualized approach to teaching abstraction, increasing the transactional distance between the concept and its application, whereas the second example situated the context authentically. Authentic learning tasks are more complex with many possible solutions requiring a higher cognitive load to complete successfully (van Merriënboer et al., 2006; van Merriënboer \& Sweller, 2010). Further, foundational cognitive psychology research holds that increased prior experience or interest in a subject contributes to a willingness to exert more cognitive effort when learning and practicing the subject (Wang \& Andre, 1991). Thus, if we consider that the secondary learners had prior experience or interest with the subject through previous coursework and personal activities than the primary learners, it comes as no surprise that they found success with an authentic abstraction activity. On the other hand, the teachers, who are adult learners, may have had an interest but chose to participate in the workshops due to a lack of prior experience. The complexity of the task thus necessitated a macro approach to reduce the cognitive load necessary for the learners. What about their interests, however (Kanfer \& Ackerman, 1989)? What role might interest play when prior experience is low and we need something else to anchor new knowledge?

Judgment day: Activating computational thinking activities with popular culture. Tonia A. Dousay. 


\section{Motivation}

Personal desires form the foundation of motivation. Generally speaking, being motivated means a desire to know or do something; without a reason or inspiration to act, a person is unmotivated (Deci \& Ryan, 2000). In other words, our state of excitement or arousal finds inspiration in specific reasons or goals that underlie the action. When a person draws upon personal interests and curiosities, we refer to their motivation as intrinsic, and when these goals connect to separable outcomes like rewards or status, we refer to the motivation as extrinsic (Deci \& Ryan, 1980, 1985, 1991). We must attend to these distinctions because intrinsic motivation is an important phenomenon in learning (Ryan $\&$ Stiller, 1991), and performance in and quality of a learning experience depends heavily on the source of motivation (Ryan \& Deci, 2000). The importance of intrinsic motivation for a positive outcome in a complex learning task, therefore, becomes a bridge to explore for designing better unplugged computational thinking activities.

\section{Self-Regulation}

Thus far, we have briefly explored the complexities of teaching computational thinking and described computational thinking in terms of a competency to learn. Now consider that learners are pluralistic with multiple states of reasoning that compete and cooperate, process in parallel or serial manner, and exist either activated or deactivated at any given moment (Navon, 1989; Simon, 1967). In this characterization, learners not only need to learn computational thinking, but they are also dependent on computational thinking functions. Indeed, self-regulation depends upon computational competencies, making it a metaskill (Karoly, 1993). This unique relationship forms the basis for arguing a need for attention on motivation in computational thinking education.

Regardless of age, learners must regulate their behaviors to ensure they have the resources needed to bring about their desired outcomes (Muraven et al., 2006; Shah \& Kruglanski, 2008). As learning designers, we can assist learners with this regulation by drawing upon established frameworks such as Keller's (Keller, 2010, 2016). Quality learning design considers the roles of attention, relevance, confidence, satisfaction, and volition to sequence content effectively, attend to the value of content, and select appropriate media aligned with learners' needs. These needs extend to include design considerations for mitigating cognitive load demand through designs that support self-regulation (Seufert, 2018). Thus, we might consider taking learners' interests more seriously in design as their presence in a learning activity typically results in more serious engagement, successful solutions to challenging problems, achievable goals, and demonstrated self-regulation (Harackiewicz et al., 2008; Renninger \& Bachrach, 2015; Sansone et al., 2015).

Long misunderstood, learner interest is not a specific type of motivation but plays a significant role in motivation, extending beyond basic emotions and influencing motivation (Schunk, 2008; Schunk et al., 2008). We know that prior interest level, experience, and knowledge mediate other learning differences (Chambers \& Andre, 1997). However, it also appears that a learner's interest in a concept or topic serves as the critical intrinsic motivation precursor for metacognition (Tobias, 2006). Thus, designing

Judgment day: Activating computational thinking activities with popular culture. Tonia A. Dousay. 
for learner interest has the added benefit of guiding goal-related behaviors and personal learning management due to the ability to attach affective value to the experience, thereby triggering self-regulatory processes (O'Keefe \& Linnenbrink-Garcia, 2014). It follows then that educators also have "a critical stake in supporting the development of interestas the presence of interest benefits sustained engagement and learning" (Renninger \& Hidi, 2021).

\section{Interest}

Similar to using computational thinking competencies as we learn computational thinking, we can use existing interest to stimulate interest. To do this, we must first differentiate between types of interest, individual or situational (Linnenbrink-Garcia et al., 2010), and application in learning design. Individual interest associates positive emotions with a topic or activity and ascribes personal value or significance to the topic or activity (Krapp et al., 1992; Rathunde, 1993; Renninger, 2000; Renninger et al., 1992; Schiefele, 1991). Subject to context or environment, situational interest emerges as an affective response based on individual interest (Hidi \& Anderson, 1992; Hidi \& Baird, 1986; Krapp, 2002; Renninger \& Hidi, 2002). Practically speaking, a learner's previous positive exposure to or experiences with a subject can translate into increased individual interest in the subject, and future encounters with this subject can trigger or initiate interest, perpetuating a cycle (Merrill, 2018).

Previous research on situational interest in the learning environment focused on types of tasks (Chen et al., 2001), role/actions of the instructor (Linnenbrink-Garcia et al., 2010), classroom environment (Corkin et al., 2014), applications of collaboration and competition (Plass et al., 2013), and multimedia designs (Dousay, 2016). These studies provide guidance on why and how to design for interest in learning with differing approaches to measuring impact. When Palmer et al. (2016) examined underlying factors contributing to situational interest in a science class for preservice teachers, they focused on conceptual constructs of relevance (usefulness for future application and novelty (new or unusual), highlighting the role of physical activity social interactions as minor contributors to situational interest. However, the researchers also noted using specific techniques such as models, science toys, games, and magic to generate situational interest. The relationship between these techniques and why they were successful eludes discussion in the cognitive psychology literature but may find justification in the learning, design, and technology literature.

\section{Activation Principle}

Returning to our computational thinking learning context, we accept two assumptions. First, complex learning tasks require integrating and applying new knowledge, skills, and attitudes into authentic applications (van Merriënboer et al., 2003; van Merriënboer \& Sweller, 2005). Second, problems in learning tasks must be interesting, engaging, and relevant for learners to assume ownership and assign (Jonassen, 1999). However, this perspective also requires a more broad view of the steps involved in this process. For this aspect of the discussion, we turn to Merrill (2002) First Principles of Instruction, and more specifically, the Activation Principle: "Learning is promoted when relevant previous experience is activated. Corollary-Learning is promoted when learners are

Judgment day: Activating computational thinking activities with popular culture. Tonia A. Dousay. 
directed to recall, relate, describe, or apply knowledge from relevant past experience that can be used as a foundation for the new knowledge" (p. 46). We take advantage of existing mental models when we activate learning, facilitating adaptation and learners' acceptance of new knowledge and skills (Merrill, 2018). Hence, it is within activation that we find a genuine link between computational thinking and situational interest as a learning design framework.

Mental models operationalize the relationships between existing knowledge, past experiences, present challenges, and future applications as we learn new information and take action (Craik, 1943; Johnson-Laird, 1980). Foundational to modal cognition, our ability to reason, form new connections, and take action relies heavily on personal judgments of probability and value (Phillips et al., 2019). In other words, when faced with new information, a person's mental model helps them evaluate the likelihood of encountering the information again and situational reward. If the new information bears a relationship with an existing or prior interest, a learner's mental model may recognize and prioritize the connection, providing even marginal learning gains (Cachia et al., 2014).

To date, the few examples of the activation principle in STEM learning focus on providing a familiar context for association or drawing upon previous experience external to the learning context. Kuba et al. (2021) used familiar gameplay level contexts and balanced multimedia elements to help activate and trigger situational interest when designing a physics game for secondary learners. This approach provided a visual reference during content presentation for learners to recognize during practice tasks. Represent a leveraging approach, (Bhattacharya \& Brown, 2020) used learners' previous knowledge of directions and related visual symbols to activate learning simple programming with early elementary students using Bee-Bots. This approach uses existing knowledge (e.g., a left arrow points left $\leftarrow$ and a right arrow points right $\rightarrow$ ) to facilitate learning a new application and skill. Similarly, physics learners in Ethiopian universities experienced the activation principle by answering related topical questions asking them to associate concepts with prior experience and sharing their responses with peers (Tiruneh et al., 2017). While these examples may inspire researchers and learning designers, the opportunity exists to extend the concept of activation in STEM learning, incorporating the affordances of situational learning and exploring the more nuanced role of techniques using popular culture.

\section{Unplugged Activation with Popular Culture}

In their review of more than 200 publications relating to National Science Foundation ITEST projects, Vogt et al. (2016) noticed a trend to make STEM learning relevant with inspiration from popular culture. For example, using "forensics-focused mystery games to engage students who are familiar with television crime dramas in learning biology concepts" (p. 2). Earlier described unplugged computational thinking activities used a similar approach, though the strategies were untested. Recall that Rodriguez et al. (2017) contextualized their activity with generalized interesting story characters (Delilah the Dog and Carnival Fortuneteller) and Brackmann et al. (2017) incorporated a popular children's song for one of their activities. Even the use of magic in the studies from Curzon et al.

Judgment day: Activating computational thinking activities with popular culture. Tonia A. Dousay. 
(2014) and Palmer et al. (2016) demonstrate a generalized approach to pop culture integration. However, these studies lack the detail necessary to properly evaluate possible impacts on situational interest or use as an activation for learning.

Branded examples of popular culture in STEM learning prove just as elusive in the literature. Jamaludin and Hung (2017) explored the use of Warcraft, a massive multiplayer online role-playing game (MMORPG) with Singaporean youth, but the study looked at problem-solving development and did not consider the context as a framework construct, whether situational interest or activation. Although not grounded in activation or situational interest, Längle (2019) explored the suitability of Star Wars as a reference for STEM instruction and appropriate applications. His findings highlight applications in adult learning and how to use the popular culture franchise to engage learners in discussions about science fiction or robotics instruction. Again, the opportunity to consider and study popular culture as a situational interest trigger and activation strategy for learners presents itself.

Examples of ways to potentially integrate popular culture into STEM for activation in unplugged computational thinking might draw upon various pop culture references and take three approaches: familiar characters, stories, and/or media. Familiar characters take advantage of popular shows to situate a problem and evoke an empathetic response from the learner. For example, learners might find themselves exploring with Dora or Diego (see Nickelodeon's Dora the Explorer), solve a mystery with Elsa and Anna (see Disney's Frozen), or fix a broken starship engine with Geordi (see Star Trek: The Next Generation). Familiar stories incorporate famous problems or challenges from popular culture. In this case, learners might need to provide an alternate solution to the alien invasion from Independence Day. Lastly, using popular music for specific activities, such as converting a song to an algorithm, serves as an exemplar strategy to consider. Transformational creativity serves as the motivator in this last example.

\section{Evaluating the concept}

When applied in computational thinking activities specifically, this conceptual framework aligns the use of popular culture with (Zapata-Ros, 2018) goal of evoking positive memories and enhance other stages of learning disconnected from the initial learning experience. The use of situational interest as a theoretical grounding for activation provides an empirical method to study and interpret findings. Methods for measuring situational interesting include observation and self-report (see Dousay and Trujillo, 2019). When paired with validated computational thinking assessments, robust studies can effectively consider both the potential for popular culture to activate learning and learner's skill achievement.

\section{Limitations}

A significant limitation of this framework rests in application. Using interest as a learning design strategy represents a situational application of the activation principle. (Reigeluth \& Carr-Chellman, 2009) characterized situational principles of learning as existing along a continuum from very common to insular and are necessary considerations as we align learning design to the needs of our learners and learning goals. Designing an optimal learning system (e.g., unplugged computational thinking activity) requires situationally

Judgment day: Activating computational thinking activities with popular culture. Tonia A. Dousay. 
attending to the motivations, interests, and prior experiences of learners. We must be careful when selecting popular culture references and resources and consider the perspectives of our learners.

For example, physics lessons sometimes draw upon sports to provide a familiar context and tangible reference for abstract concepts. However, not all learners have positive sports memories and experiences, resulting in no motivational interest (Merrill, 2018), or worse, disengagement from the activity. Additionally, learner gender often stands out as a significant factor to consider. Wulff et al. (2018) noted gender differences in specific physics content interests; thus, it stands to reason those similar differences extend to interests in popular culture. Age of our learners also plays an important role. Brackmann et al. (2017) found that older students did not like the musical algorithm task because it was considered a children's song for little kids. Lastly, cultural differences contribute to relevance. Returning to the sports analogy, learning designers may experience success using soccer or fútbol references in American classrooms but failure when using American football references in some international classrooms. Similarly, stories and characters often have cultural boundaries. While streaming media services facilitate broader international film and television distribution, relevance and favor cannot be assumed. A proper analysis of learners, identifying what popular culture resonates with the group, must be conducted.

When considering multimedia, such as background music during a learning experience, (Merrill, 2020) cautions designers to consider cognitive and affective dilemmas. For example, unrelated music may distract learners, and familiar music may activate unrelated mental models, contributing to cognitive overload. Though the current framework proposes using media more actively, the challenges discussed herein are both affective and cognitive. At best, a misaligned selection goes unnoticed and provides no value to the experience. At worst, the error could have severe motivational consequences, leading to disengagement and negative memories. Edwards (2015) noted that an increased emphasis on play has brought about a need for more research on how to effectively and confidently integrate popular culture. Learning designers and scholars might consider drawing upon empathy in education literature (see Feshbach and Feshbach, 2009) and concepts such as empathy personas and maps (see Wertz et al., 2020). Learner interests and responsiveness to pop culture triggers represent both limitations and potential inquiry, investigating when specific examples stimulate or impair interest.

\section{Conclusion}

Dewey $(1913,1933,1938)$ first noted that interest is an active state based on authentic engagement with highly personal meaning, hinting at its possible role in learning. A century of research since, and we have a better understanding of how a learner's individual interest contributes to situational interest and how this interest perpetuates a cycle of learning and positive affective experiences. As a theoretical framework, situational interest operationalizes the Activation Principle in learning design, providing an empirical means to investigate different strategies for activating learning. Situational interest also represents a connection to self-regulation, a computational process underlying motivation. Wrapping the framework in the metaskill of computational thinking makes it uniquely appropriate for investigations of unplugged activities. As with

Judgment day: Activating computational thinking activities with popular culture. Tonia A. Dousay. 
many wicked problems facing education today, a practical design-based research study could effectively integrate the framework for appropriateness and future implications.

Received: June, 23, 2021

Accepted: November, 03, 2021

Published: November 30, 2021

Dousay, Tonia A. (2021). Judgment day: Activating computational thinking activities with popular culture. RED. Revista Educación a Distancia, 21(68). http://dx.doi.org/10.6018/red.485621

\section{Funding}

This research has not received any specific grant from funding agencies in the public, commercial or non-profit sectors.

\section{References}

Alsup, P., \& Ford, A. (2017). Planning science classroom facilities and resources to improve students' attitudes. Educational Planning, 24(4), 27-48.

Alvermann, D. E., Moon, J. S., \& Hagood, M. C. (1999). Popular culture in the classroom: Teaching and researching critical media literacy. International Reading Association.

Bell, T., \& Roberts, J. (2016). Computational thinking is more about humans than computers. Set: Research Information for Teachers, 1, 3-7. https://doi.org/10.18296/set.0030

Bhattacharya, P., \& Brown, M. (2020). Bee-Bot for computational thinking: An artifact analysis. In D. A. Schmidt-Crawford (Ed.), Proceedings of Society for Information Technology \& Teacher Education International Conference (pp. 2-7). Online: Association for the Advancement of Computing in Education (AACE). https://www.learntechlib.org/p/215724

Brackmann, C. P., Moreno-León, J., Román-González, M., Casali, A., Robles, G., \& Barone, D. (2017). Development of computational thinking skills through unplugged activities in primary school. ACM International Conference Proceeding Series, 65-72. https://doi.org/10.1145/3137065.3137069

Cachia, W., Aquilina, L., Martinez, H. P., \& Yannakakis, G. N. (2014). Procedural generation of music-guided weapons. IEEE Conference on Computational Intelligence and Games, CIG, 2080, 1-2. https://doi.org/10.1109/CIG.2014.6932925

Caeli, E. N., \& Yadav, A. (2020). Unplugged approaches to computational thinking: A historical perspective. TechTrends, 64(1), 29-36. https://doi.org/10.1007/s11528-019-00410-5

Chambers, S. K., \& Andre, T. (1997). Gender, prior knowledge, interest, and experience in electricity and conceptual change text manipulations in learning about direct current. Journal of Research in Science Teaching, 34(2), 107-123. https://doi.org/10.1002/(SICI)10982736(199702)34:2<107::AID-TEA2>3.0.CO;2-X

Chen, A., Darst, P. W., \& Pangrazi, R. P. (2001). An examination of situational interest and its sources in physical education. British Journal of Educational Psychology, 71(3), 383-400.

Judgment day: Activating computational thinking activities with popular culture. Tonia A. Dousay. 
Corkin, D. M., Yu, S. L., Wolters, C. A., \& Wiesner, M. (2014). The role of the college classroom climate on academic procrastination. Learning and Individual Differences, 32, 294-303. https://doi.org/10.1016/j.lindif.2014.04.001

Craik, K. J. W. (1943). The nature of explanation. University Press, Macmillan.

Cunningham, J. (2014). Use science fiction to teach STEM, inspire innovation. Education World. https://www.educationworld.com/a_curr/science-fiction-stem-engagement-technology.shtml

Curzon, P., McOwan, P. W., Plant, N., \& Meagher, L. R. (2014). Introducing teachers to computational thinking using unplugged storytelling. 89-92. https://doi.org/10.1145/2670757.2670767

Deci, E. L., \& Ryan, R. M. (1980). The empirical exploration of intrinsic motivational processes. In L. Berkowitz (Ed.), Advances in Experimental Social Psychology (pp. 39-80). Academic.

Deci, E. L., \& Ryan, R. M. (1985). Intrinsic motivation and self-determination in human behavior. Plenum.

Deci, E. L., \& Ryan, R. M. (1991). A motivational approach to self: Integration in personality. In R. Dienstbier (Ed.), Nebraska Symposium on Motivation: Vol. 38. Perspectives on Motivation (pp. 237-288). University of Nebraska Press.

Deci, E. L., \& Ryan, R. M. (2000). The "what" and "why" of goal pursuits: Human needs and the self-determination of behavior. Psychological Inquiry, 11(4), 227-268.

Dewey, J. (1913). Interest and effort in education. Riverside.

Dewey, J. (1933). How we think. Heath.

Dewey, J. (1938). Experience and education. Macmillan.

Dousay, T. A. (2016). Effects of redundancy and modality on the situational interest of adult learners in multimedia learning. Educational Technology Research and Development, 64(6), 1251-1271. https://doi.org/10.1007/s11423-016-9456-3

Dousay, T. A., \& Trujillo, N. P. (2019). An examination of gender and situational interest in multimedia learning environments. British Journal of Educational Technology, 50(2), 876887. https://doi.org/10.1111/bjet.12610

Edwards, S. (2015). New concepts of play and the problem of technology, digital media and popular-culture integration with play-based learning in early childhood education. Technology, Pedagogy and Education, 25(4), 513-532. https://doi.org/10.1080/1475939X.2015.1108929

Feshbach, N. D., \& Feshbach. (2009). Empathy and education. In J. Decety \& W. Ickes (Eds.), The social neuroscience of empathy (pp. 85-97). MIT Press.

Harackiewicz, J. M., Durik, A. M., Barron, K. E., Linnenbrink-Garcia, L., \& Tauer, J. M. (2008). The role of achievement goals in the development of interest: Reciprocal relations between achievement goals, interest, and performance. Journal of Educational Psychology, 100(1), 105-122. https://doi.org/10.1037/0022-0663.100.1.105

Hidi, S. E., \& Anderson, V. (1992). Situational interest and its impact on reading and expository writing. In K. A. Renninger, S. Hidi, \& A. Krapp (Eds.), The Role of Interest in Learning and Development (pp. 215-238). Lawrence Erlbaum.

Hidi, S. E., \& Baird, W. (1986). Interestingness-a neglected variable in discourse processing. Cognitive Science, 10(2), 179-194.

Isaac, J. D., Sansone, C., \& Smith, J. L. (1999). Other people as a source of interest in an activity. Journal of Experimental Social Psychology, 35(3), 239-265. https://doi.org/10.1006/jesp.1999.1385

Judgment day: Activating computational thinking activities with popular culture. Tonia A. Dousay. 
Izu, C., Mirolo, C., Settle, A., Mannila, L., \& Stupuriene, G. (2017). Exploring Bebras tasks content and performance: A multinational study. Informatics in Education, 16(1), 39-59. https://doi.org/10.15388/infedu.2017.03

Jamaludin, A., \& Hung, D. (2017). Problem-solving for STEM learning: navigating games as narrativized problem spaces for 21 st century competencies. Research and Practice in Technology Enhanced Learning, 12(1), 1-14. https://doi.org/10.1186/s41039-016-0038-0

Johnson-Laird, P. N. (1980). Mental models in cognitive science. Cognitive Science, 4, 71-115.

Jonassen, D. (1999). Designing constructivist learning environments. In C. M. Reigeluth (Ed.), Instructional-design theories and models: A new paradigm of instructional theory (Vol. II) (pp. 215-239). Lawrence Erlbaum Associates. https://doi.org/10.4324/9781410603784-16

Kanfer, R., \& Ackerman, P. L. (1989). Motivation and cognitive abilities: An integrative/aptitudetreatment interaction approach to skill acquisition. Journal of Applied Psychology, 74(4), 657690. https://doi.org/10.1037/0021-9010.74.4.657

Karoly, P. (1993). Mechanisms of self-regulation: A systems view. Annual Review of Psychology, 44, 23-52. https://doi.org/10.1146/annurev.ps.44.020193.000323

Keller, J. M. (2010). Challenges in learner motivation: A holistic, integrative model for research and design on learner motivation. The 11th International Conference on Education Research.

Keller, J. M. (2016). Motivation, learning, and technology: Applying the ARCS-V motivation model. Participatory Educational Research, 3(2), 1-15. https://doi.org/10.17275/per.16.06.3.2

Krapp, A. (2002). An educational-psychological theory of interest and its relation to SDT. In E. L. Deci \& R. M. Ryan (Eds.), The Handbook of Self-Determination Research (Issue Csikszentmihalyi 1975, pp. 405-427). Rochester University Press.

Krapp, A., Hidi, S., \& Renninger, K. A. (1992). Interest, learning, and development. In K. A. Renninger, S. Hidi, \& A. Krapp (Eds.), The role of interest in learning and development (pp. 3-25). Erlbaum.

Kuba, R., Rahimi, S., Smith, G., Shute, V., \& Dai, C. P. (2021). Using the first principles of instruction and multimedia learning principles to design and develop in-game learning support videos. Educational Technology Research and Development, 69(2), 1201-1220. https://doi.org/10.1007/s11423-021-09994-3

Längle, S. (2019). Star Wars science on social media! Using pop culture to improve STEM skills. International Journal of Social Media and Interactive Learning Environments, 6(2), 137. https://doi.org/10.1504/ijsmile.2019.102172

Linnenbrink-Garcia, L., Durik, A. M., Conley, A. M., Barron, K. E., Tauer, J. M., Karabenick, S. A., \& Harackiewicz, J. M. (2010). Measuring situational interest in academic domains. Educational and Psychological Measurement, 70(4), 647-671.

Looi, C. K., How, M. L., Longkai, W., Seow, P., \& Liu, L. (2018). Analysis of linkages between an unplugged activity and the development of computational thinking. Computer Science Education, 28(3), 255-279. https://doi.org/10.1080/08993408.2018.1533297

Luke, C. (1997). Media literacy and cultural studies. In S. Muspratt, A. Luke, \& P. Freebody (Eds.), Constructing critical literacies: Teaching and learning textual practice (pp. 19-49). Hampton Press, Inc.

Merrill, M. D. (2002). First principles of instruction. Educational Technology Research and Development, 50(3), 43-59.

Merrill, M. D. (2018). Using the First Principles of Instruction to make instruction effective, efficient, and engaging. In R. E. West (Ed.), Foundations of learning and instructional design

Judgment day: Activating computational thinking activities with popular culture. Tonia A. Dousay. 
technologyarning and Instructional Design Technology. EdTechBooks.org. http://edtechbooks.org/lidtfoundations/using_the_first_principles_of_instruction

Merrill, M. D. (2020). Using multimedia to implement instructional strategies. In First principles of instruction, Revised edition. Association for Educational Communications \& Technology. https://aect.org/firstprinciples.php

Muraven, M., Shmueli, D., \& Burkley, E. (2006). Conserving self-control strength. Journal of Personality and Social Psychology, 91(3), 524-537. https://doi.org/10.1037/00223514.91.3.524

Naur, P. (1970). Planer og ideer for datalogisk institut ved Kobenhavns universitet. http://www.naur.com/comp/c4-6.html

Naur, P. (2005). Computing versus human thinking. A. M. Turing Award Lecture Video; ACM. https://amturing.acm.org/vp/naur_1024454.cfm

Navon, D. (1989). The importance of being visible: On the role of attention in a mind viewed as an anarchic intelligence system ii. Application to the field of attention. European Journal of Cognitive Psychology, 1(3), 215-238. https://doi.org/10.1080/09541448908403082

Nummenmaa, M., \& Nummenmaa, L. (2008). University students' emotions, interest and activities in a web-based learning environment. British Journal of Educational Psychology, 78(1), 163-178. https://doi.org/10.1348/000709907X203733

O'Keefe, P. A., \& Linnenbrink-Garcia, L. (2014). The role of interest in optimizing performance and self-regulation. Journal of Experimental Social Psychology, 53, 70-78. https://doi.org/10.1016/j.jesp.2014.02.004

Palmer, D. H., Dixon, J., \& Archer, J. (2016). Identifying underlying causes of situational interest in a science course for preservice elementary teachers. Science Education, 100(6), 1039-1061. https://doi.org/10.1002/sce.21244

Phillips, J., Morris, A., \& Cushman, F. (2019). How we know what not to think. Trends in Cognitive Sciences, 23(12), 1026-1040. https://doi.org/10.1016/j.tics.2019.09.007

Plass, J. L., O’Keefe, P. A., Homer, B. D., Case, J., Hayward, E. O., Stein, M., \& Perlin, K. (2013). The impact of individual, competitive, and collaborative mathematics game play on learning, performance, and motivation. Journal of Educational Psychology, 105(4), 10501066. https://doi.org/10.1037/a0032688

Rathunde, K. (1993). The experience of interest: A theoretical and empirical look at its role in adolescent talent development. In M. Maehr \& P. R. Pintrich (Eds.), Advances in Motivation and Achievement (8th ed., Vol. 8, pp. 59-98). JAI Press.

Reeve, J. (1989). The interest-enjoyment distinction in intrinsic motivation. Motivation and Emotion, 13(2), 83-103. https://doi.org/10.1007/BF00992956

Reeve, J., Bolt, E., \& Cai, Y. (1999). Autonomy-supportive teachers: How they teach and motivate students. Journal of Educational Psychology, 91(3), 537-548. https://doi.org/10.1037/0022-0663.91.3.537

Reigeluth, C. M., \& Carr-Chellman, A. A. (2009). Situational principles of instruction. In Instructional-design theories and models: Vol. III (pp. 57-68). Routledge.

Renninger, K. A. (2000). Individual interest and its implications for understanding intrinsic motivation. In J. M. Harackiewicz \& C. Sansone (Eds.), Intrinsic and Extrinsic Motivation: The Search for Optimal Motivation and Performance (pp. 373-404). Academic Press.

Renninger, K. A., \& Bachrach, J. E. (2015). Studying triggers for interest and engagement using observational methods. Educational Psychologist, 50(1), 58-69. https://doi.org/10.1080/00461520.2014.999920

Judgment day: Activating computational thinking activities with popular culture. Tonia A. Dousay. 
Renninger, K. A., \& Hidi, S. E. (2002). Student interest and achievement: Developmental issues raised by a case study. In A. Wigfield \& J. S. Eccles (Eds.), Development of achievement motivation. A volume in the educational psychology series (pp. 173-195). Academic Press.

Renninger, K. A., \& Hidi, S. E. (2021). Interest development, self-related information processing , and practice. Theory Into Practice. https://doi.org/10.1080/00405841.2021.1932159

Renninger, K. A., Hidi, S. E., \& Krapp, A. (1992). The role of interest in learning and development. Lawrence Erlbaum.

Rodriguez, B., Kennicutt, S., Rader, C., \& Camp, T. (2017). Assessing computational thinking in CS unplugged activities. Proceedings of the Conference on Integrating Technology into Computer Science Education, ITiCSE, 501-506. https://doi.org/10.1145/3017680.3017779

Ryan, R. M., \& Deci, E. L. (2000). Intrinsic and extrinsic motivations: Classic definitions and new directions. Contemporary Educational Psychology, 25(1), 54-67.

Ryan, R. M., \& Stiller, J. (1991). The social contexts of internalization: Parent and teacher influences on autonomy, motivation and learning. In P. R. Pintrich \& M. L. Maehr (Eds.), Advances in Motivation and Achievement (pp. 115-149). JAI Press.

Sansone, C., Thoman, D. B., \& Fraughton, T. (2015). The relation between interest and selfregulation in mathematics andd science. In K. A. Renninger, M. Nieswandt, \& S. E. Hidi (Eds.), Interest in K-16 mathematics and science learning and related activity (pp. 111-131). American Educational Research Association.

Schiefele, U. (1991). Interest, learning, and motivation. Educational Psychologist, 26(3), 299323. https://doi.org/10.1207/s15326985ep2603\&4_5

Schunk, D. H. (2008). Metacognition, self-regulation, and self-regulated learning: Research recommendations. Educational Psychology Review, 20(4), 463-467.

Schunk, D. H., Pintrich, P. R., \& Meece, J. (2008). Motivation in Education: Theory, Research, and Applications (3rd ed.). Pearson Education, Inc.

Seufert, T. (2018). The interplay between self-regulation in learning and cognitive load. Educational Research Review, 24(August 2017), 116-129. https://doi.org/10.1016/j.edurev.2018.03.004

Shah, J. Y., \& Kruglanski, A. W. (2008). Structural dynamics: The challenge of change in goal systems. In J. Y. Shah \& W. L. Gardner (Eds.), Handbook of motivation science (pp. 217229). The Guilford Press.

Silva, D. (2019, December). Science fiction: Why you should be using it with your students! Infusing Technology. https://teachersfirst.com/blog/2019/12/science-fiction-why-you-shouldbe-using-it-with-your-students/

Simon, H. A. (1967). Motivational and emotional controls of cognition. Psychological Review, 74(1), 29-39. https://doi.org/10.1037/h0024127

Strauss, M. (2012, March). Ten inventions inspired by science fiction. Smithsonian Magazine.

Tiruneh, D. T., Cock, M. de, Spector, J. M., Gu, X., \& Elen, J. (2017). Toward a systematic and model-based approach to design learning environments for critical thinking. In J. M. Spector \& B. B. Lockee (Eds.), Learning, design, and technology: An international compendium of theory, research, practice, and policy. Springer. https://doi.org/10.1007/978-3-319-177274_79-1

Tobias, S. (2006). The importance of motivation, metacognition, and help seeking in web-based learning. In H. F. O'Neil Jr. \& R. S. Perez (Eds.), Web-Based Learning: Theory, Research and Practice (pp. 203-220). Lawrence Erlbaum Associates.

Judgment day: Activating computational thinking activities with popular culture. Tonia A. Dousay. 
Trier, J. (2006). Teaching with media and popular culture. Journal of Adolescent \& Adult Literacy, 49(5), 434-438. https://doi.org/10.1598/jaal.49.5.7

van Merriënboer, J. J. G., Kester, L., \& Paas, F. (2006). Teaching complex rather than simple tasks: Balancing intrinsic and germane load to enhance transfer of learning. Applied Cognitive Psychology, 20(3), 343-352. https://doi.org/10.1002/acp.1250

van Merriënboer, J. J. G., Kirschner, P. A., \& Kester, L. (2003). Taking the load off a learner's mind: Instructional design for complex learning. Educational Psychologist, 38(1), 5-13. https://doi.org/10.1207/S15326985EP3801_2

van Merriënboer, J. J. G., \& Sweller, J. (2005). Cognitive load theory and complex learning: Recent developments and future directions. Educational Psychology Review, 17(2), 147-177.

van Merriënboer, J. J. G., \& Sweller, J. (2010). Cognitive load theory in health professional education: Design principles and strategies. Medical Education, 44(1), 85-93. https://doi.org/10.1111/j.1365-2923.2009.03498.x

Vogt, K. A., Remold, J., \& Parker, C. E. (2016). STEM learning games and game design in ITEST projects.

Wang, T., \& Andre, T. (1991). Conceptual change text versus traditional text and application questions versus no questions in learning about electricity. Contemporary Educational Psychology, 16(2), 103-116. https://doi.org/10.1016/0361-476X(91)90031-F

Wertz, R. E. H., Fila, N. D., Smith, K. A., \& Streveler, R. A. (2020). How do I understand them? Integrating empathy into course design through personas. Proceedings - Frontiers in Education Conference, FIE, 4-6. https://doi.org/10.1109/FIE44824.2020.9274152

Wing, J. M. (2006). Computational thinking. Communications of the ACM, 49(3), 33-35. https://doi.org/10.1145/1118178.1118215

Wing, J. M. (2008). Computational thinking and thinking about computing. Philosophical Transactions of the Royal Society A: Mathematical, Physical and Engineering Sciences, 366(1881), 3717-3725. https://doi.org/10.1098/rsta.2008.0118

Wulff, P., Hazari, Z., Petersen, S., \& Neumann, K. (2018). Engaging young women in physics: An intervention to support young women's physics identity development. Physical Review Physics Education Research, 14(2), 20113. https://doi.org/10.1103/PhysRevPhysEducRes.14.020113

Zapata-Ros, M. (2018). Computational thinking in the first educational cycles, unplugged computational thinking (I1). RED Hypotheses Blog. Learning in the Knowledge Society. https://doi.org/10.14201/eks2019_20_a18

Judgment day: Activating computational thinking activities with popular culture. Tonia A. Dousay. 